\title{
Rescue Coronary Angioplasty in a Patient with Acute Myocardial Infarction and Myocardial Bridge
}

\author{
José Augusto Rocha Araújo, Nilson Moura Fé Fo, Flávio José Rocha de Souza, Aluísio Cruz Jr, \\ Sandro Salgueiro Rodrigues, Frederico Augusto de Lima e Silva
}

\author{
Fortaleza, CE - Brazil
}

\begin{abstract}
Myocardial bridge (MB) is an infrequent angiographic finding, with an incidence ranging from $0.5 \%$ to $2.5 \%{ }^{1}$. At autopsy, however, it has ranged from $15 \%$ to $85 \%{ }^{2,3}$. Most patients with $\mathrm{MB}$ are asymptomatic but, when symptoms are present, patients may have angina ${ }^{4}, \mathrm{AMI}{ }^{1,5,6}$, and even sudden death ${ }^{7}$. The exact mechanism through which MB induces myocardial ischemia is currently unknown, making the identification and therapy of this condition more difficult. Medical management has included aspirin, calcium antagonists, and beta-blockers, although the efficacy of these drugs in preventing ischemic complications has not yet been proved ${ }^{1,8}$. Reports of coronary intervention with ballooncatheter and stent in patients with MB and angina or AMI have been described in the literature ${ }^{1,9,10}$.

In this report, we a describe successful rescue coronary angioplasty in a patient who failed to respond to thrombolytic therapy. We have not found any similar reports in the literature.
\end{abstract}

\section{Case report}

A 61-year-old male mulatto patient arrived at the ED with severe squeezing chest pain, dyspnea, diaphoresis, nausea and, vomiting that had begun 3 hours prior to arrival at the ED.

On physical examination, the patient was anxious and in pain. He was hydrated, acyanotic, tachypneic, and showed no signs of disorientation. His heart rate was regular, he had an audible fourth heart sound and no heart murmurs; his blood pressure was $140 / 80 \mathrm{mmHg}$, his heart rate was $100 \mathrm{bpm}$, and his respiratory rate was $24 / \mathrm{min}$. The electrocardiogram (ECG) showed AMI of the anterior wall (fig. 1).

The patient was admitted to the Intensive Care Unit (ICU) where, after cardiac monitorization and oxygen, $200 \mathrm{mg}$ of aspirin, and sublingual nitrate were administered, he was given 1,500,000 units of streptokinase IV in (1 hour). Because the clinical and electrocardiographic findings

Hospital de Messejana - SUS - Fortaleza

Mailing address: José Augusto Rocha Araújo - Rua Vicente Leite, 497/300 60170-150 - Fortaleza, CE - Brazil persisted 30 minutes after the infusion, a rescue coronary angioplasty was tried. At that moment, intravenous nitroglycerin was begun.

The patient was admitted to the cath Lab 1 hour after the end of the streptokinase infusion and 5 hours after symptom onset. A coronary angiography using the Sones technique was performed and showed total occlusion of the ADA (fig. 2A), as well as moderate ventricular dysfunction (anteroapical wall). The remaining vessels were normal. Percutaneous transluminal coronary angioplasty (PTCA) was performed with the use of a 30/20 balloon and 0.14 guide wire. Total recanalization of the vessel was achieved. The symptoms completely disappeared and the left ventricular function returned to normal (fig. 2B and C). The ECG performed after the patient was transferred to the ICU showed significant improvement (fig. 1). Two days after the procedure, the patient complained of retrosternal discomfort, consistent with angina. He underwent a second coronary angiography, which showed a patent ADA, with a significant systolic constriction in the exact site of the obstruction (fig 3). The patient was then treated with calcium antagonists and aspirin, and remaining asymptomatic.

\section{Discussion}

$\mathrm{MB}$ is an infrequent angiographic finding, with an incidence ranging from $0.5 \%$ to $2.5 \%{ }^{1}$. However, some authors ${ }^{4}$ estimate that the actual incidence of MB reaches $5 \%$ in the general population. Channer et al ${ }^{11}$, after a consecutive review of 1,000 coronary angiographies, found an incidence of $1.4 \%$ for MB in the ADA. Autopsy studies have shown an incidence of $\mathrm{MB}$ as high as $85 \%$ 2,3. The presence of MB, which is considered a benign condition, in the ADA would be protective because it prevents the development of significant atherosclerosis in the affected area ${ }^{12}$. The coexistence of MB and significant atherosclerosis has been rarely reported ${ }^{13}$.

The mechanism through which patients with MB develop ischemia or MI has not been clarified. Spasm and systolic constriction of the artery, with subsequent damage to the underlying endothelium may facilitate platelet deposition, leading to thrombus formation and to clinical findings of unstable angina and $\mathrm{MI}^{1,14}$. Ge et $\mathrm{al}^{2}$, in a compa- 


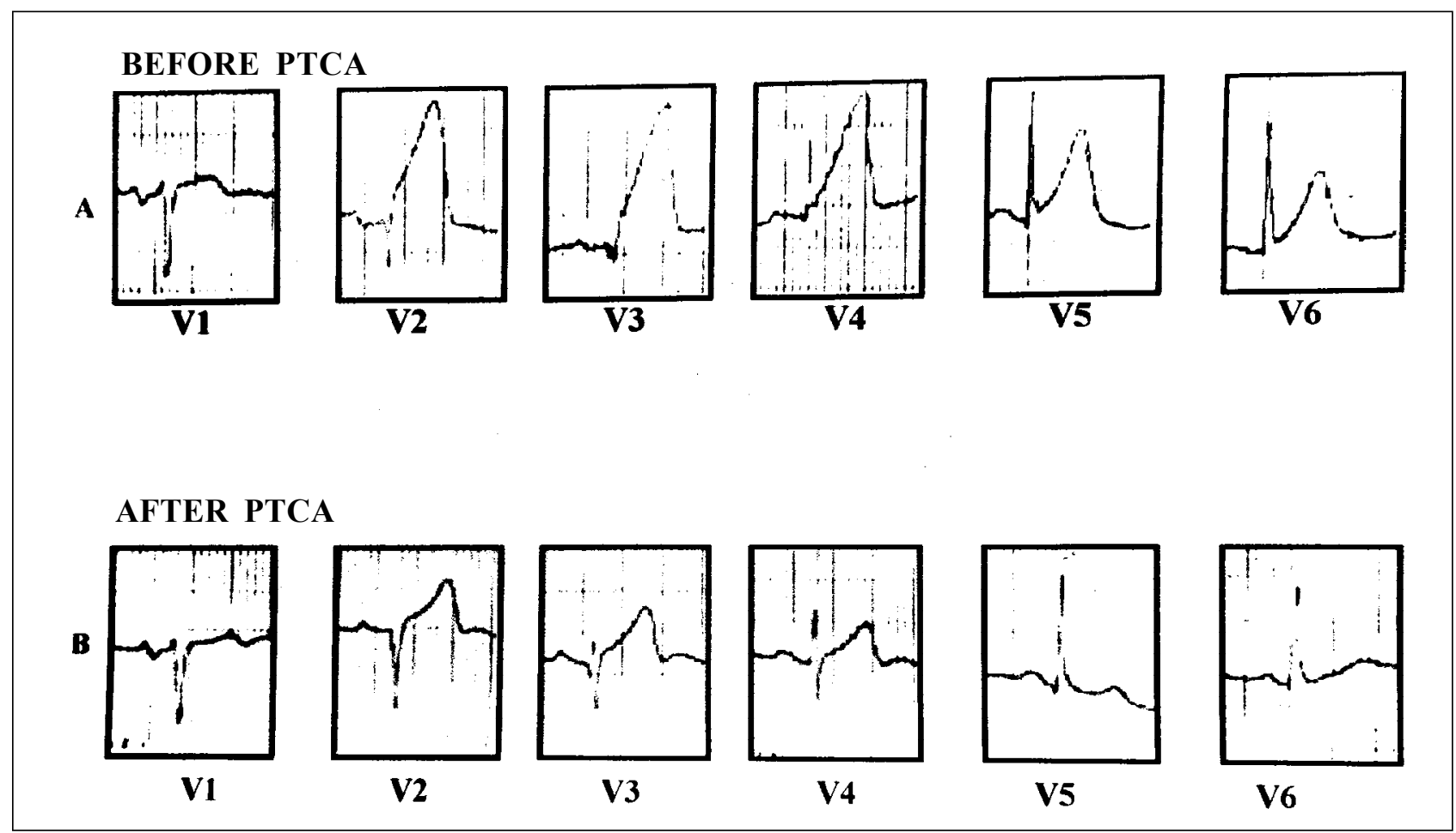

Fig 1 - A) Electrocardiogram prior to angioplasty (PTCA); B) Electrocardiogram 4h after rescue angioplasty.

rative study of coronary angiography with intracoronary ultrasound in 14 patients with MB, found that an atherosclerotic plaque was present in 12 patients $(86 \%)$ in the proximal portion of the $\mathrm{MB}$ and that the distal portion was normal. MB may alter the distribution of physical forces against the arterial wall, thus playing a role in the development of atherosclerosis in the proximal portion ${ }^{2,15,16}$.

There are reports observing that the thickness of the arterial intima in the vicinity of the MB is up to 6 times the thickness of the distal portion. This implies that the impairment of blood flow and the high proximal stress may play a role in the development of atherosclerosis in this segment of the vessel ${ }^{15}$. Morales et $\mathrm{al}^{7}$ performed necropsy in $3 \mathrm{pa}$ tients with sudden death and MB in the ADA and found an atheromatous lesion of the proximal segment in two of these patients. In our patient, because the intracoronary ultrasound was not used, we could not demonstrate presence or absence of proximal atherosclerosis. However, the hypothesis of proximal atheromatosis, seems acceptable, as well as an endothelial lesion caused by repeated contractions in the segment of the MB, which would account for the development of an acute ischemic syndrome in these patients. Juliere et $\mathrm{al}^{17}$ evaluated 61 patients with $\mathrm{MB}$ in the long-term. All their patients had an uneventful outcome. Therefore, their prognosis was considered good, regardless of the obstruction. This finding gives additional support to the hypothesis that the occurrence of spasm, endothelial lesions or proximal atherosclerosis would be needed to trigger ischemic syndromes.

More recently, with the emergence of angioplasty and of coronary stenting, a series of studies describing successful interventions in MB have been reported 1,9,10,15. Most reports are more related to the use of stents ${ }^{1,9,15}$, as they are correlated with a better immediate outcome. However, in our

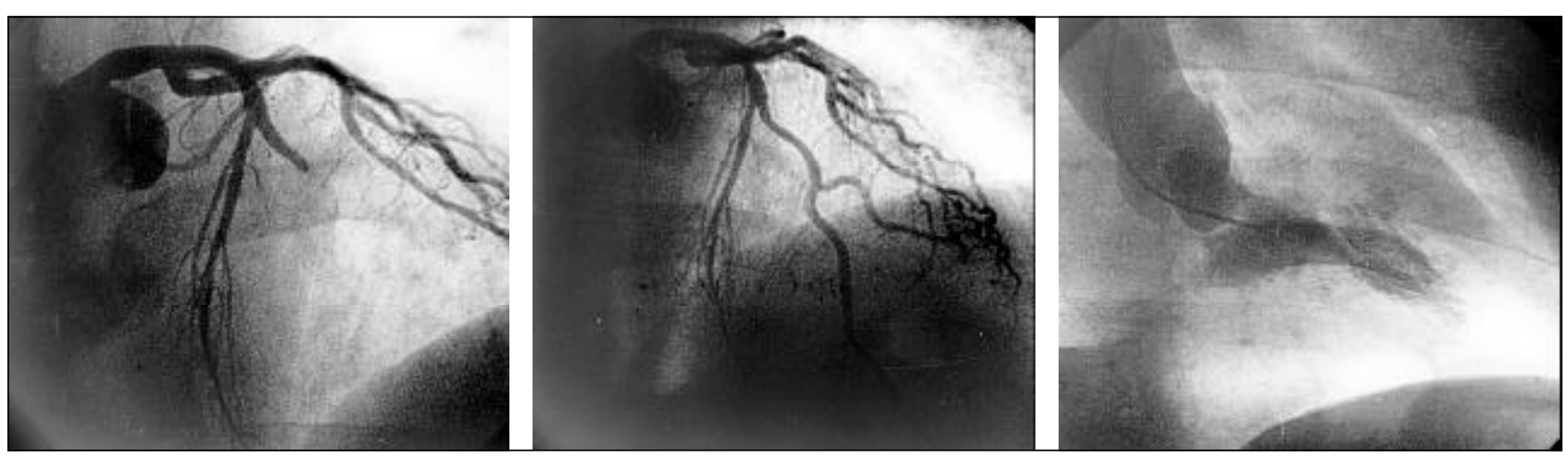

Fig 2 - A) Occlusion of the distal third of the anterior descending artery; B) Outcome after rescue angioplasty; C) The left ventricular function returned to normal. 


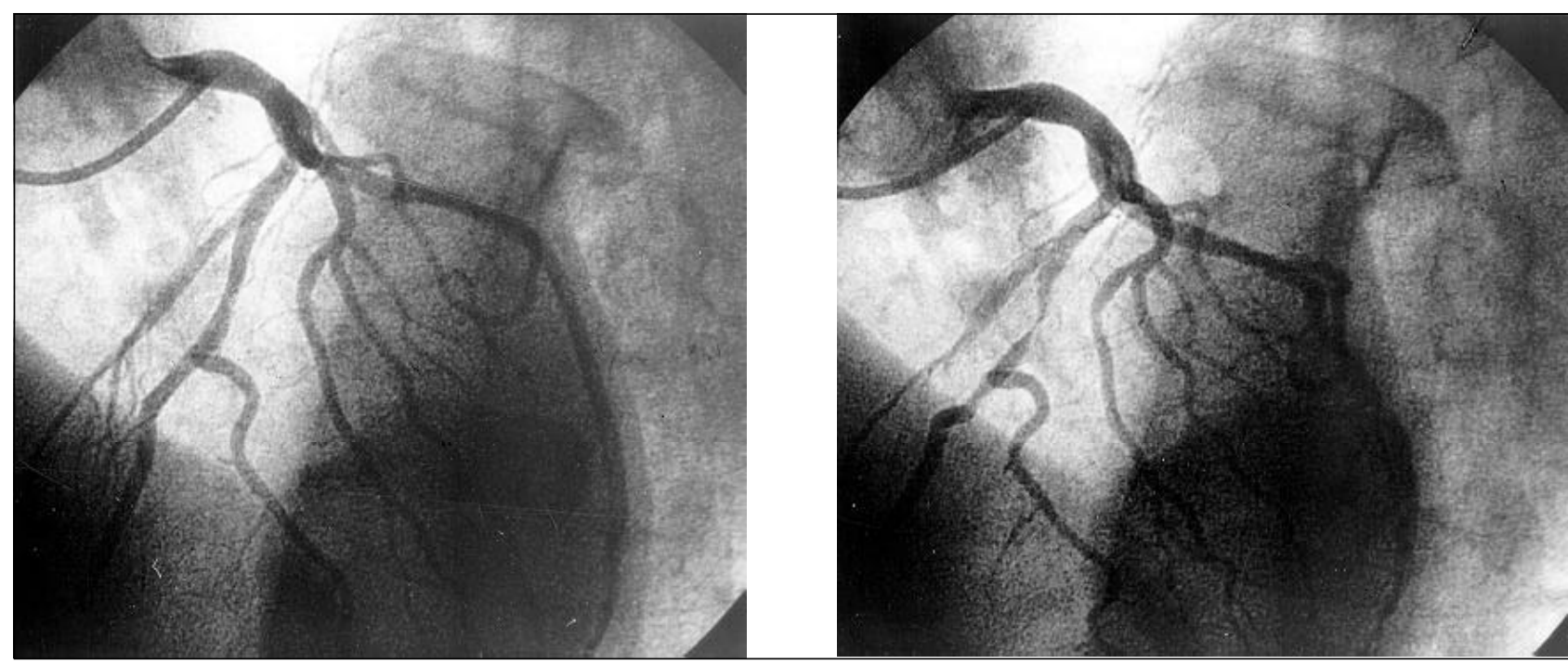

Fig 3 - A) Anterior descending artery (LAO) during diastole and B) during systole, showing the systolic compression of the vessel, which is consistent with myocardial bridge, in the occlusion site.

case, a good angiographic outcome was achieved with the use of balloon alone, which was maintained at least until the $2^{\text {nd }}$ day. This shows that angioplasty is also effective in this group of patients. We did not find in the literature any report of rescue angioplasty in patients with MB.

The effectiveness of coronary intervention has been proved in patients with $\mathrm{MB}$ and acute complications, such as AMI, and chronic complications, such as angina. PTCA seems to be a safe and effective therapeutic option for coronary recanalization of arteries with MB. However, evaluation of additional cases and further experience with follow-up are required.

\section{References}

1. Smith SC, Taber M, Robiolio PA, et al. Acute myocardial infarction caused by a myocardial bridge treated with coronary stenting. Cathet Cardiovasc diagn 1997; 42: 209-12.

2. Ge J, Erbel R, Ruprecht H. Comparison of intravascular ultrasound and angiography in the assessment of myocardial bridging. Circulation 1994; 89: 1725-32.

3. Ferreira AG, Trotter SE, Konig B, et al. Myocardial bridges. Morphological and functional aspects. Br Heart J 1991; 66: 364-7.

4. Angelini P, TrivellatoM, Donis J, et al. Myocardial Bridges: A review. Prog Cardiovasc Dis 1983; 24: 75-87.

5. Jorge PAR, Coelho OR, Fortuna ABP. Infarto do miocárdio provocado por ponte miocárdica. Apresentação de um caso. Arq Bras Cardiol 1982; 173-5.

6. Vasan RS, Bahl VK, Rajam M. Myocardial infarction associated with a myocardial bridge. Int J Cardiol 1989; 25: 240-1.

7. Morales AR, Romanelli R, Boucke RJ. The mural left anterior descending coronary artery, strenuous exercise and sudden death. Circulation 1980; 62: 230-5.

8. Feldman A, Baughman K. Myocardial infarction associated with a myocardial bridge. Am Heart J 1986; 111: 784-7.

9. Nogueira JWN, Matos RB. Implante de stent em lesão complexa de coronária descendente anterior com ponte miocárdica - relato de caso. Rev Bras Cardiol Invasiva 1996; 4: 28-31.
10. Cohen HM, Juska J, Kleiman JH. PTCA of complex atherosclerotic lesion at site of LAD myocardial bridging. Cathet Cardiovasc Diagn 1996; 37: 272-6.

11. Channer KS, Bukis E, Hartnell G, et al. Myocardial bridging of the coronary arteries. Clin Radiol 1989; 40: 355-9.

12. Bashour TT, Espinosa E, Blumenthal J, et al. Myocardial infarction caused by coronary artery myocardial bridge. Am Heart J 1997; 133: 473-7.

13. Parashara DK, Ledley GS, Koller MN, et al. The combined presence of myocardia bridging and fixed coronary artery stenosis. Am Heart J 1993; 125: 1170-2.

14. Ciampricotti R, el Gamal M. Vasospastic coronary occlusion associated with a myocardial bridge. Cathet Cardiovasc Diagn 1988; 14: 118-20.

15. Agirbasli M, Hillegass Jr WB, Chapman GD, et al. Stent procedure complicated by thrombus formation distal to the lesion within a muscle bridge. Cathet Cardiovasc Diagn 1998; 43: 73-6.

16. Kuhn FE, Reagan K, Mohler ER, et al. Evidence for endothelial dysfunction and enhanced vasoconstriction in myocardial bridges. Am Heart J 1991; 122: 1764-6.

17. Juliere Y, Berder V, Suty-Selton C, et al. Isolated myocardial bridges with angiographic milking of the left anterior descending coronary artery: a long-term follow-up study. Am Heart J 1995; 129: 663-5. 